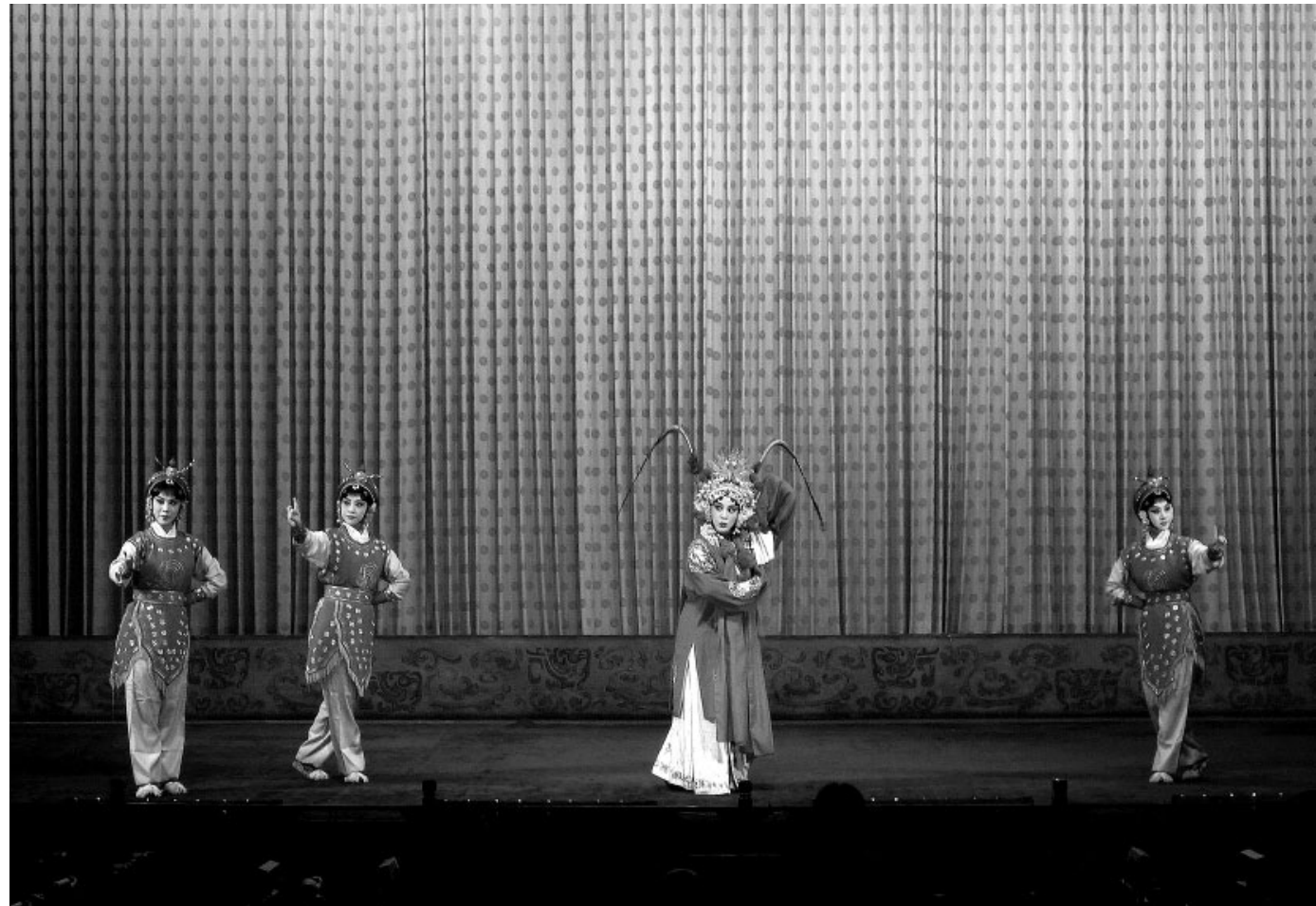

Teatro Liyuan

A fada Lingbo depois de

ter oferecido uma pérola ao Principe Baiyong como expressão do seu amor [Arquivo da autora].

\title{
O Teatro Liyuan e a sua Ópera de Pequim Percepções intuitivas de uma tradição artística oriental
}

\section{Anabela Mendes}

1.

Situado entre quarteirões demasiado ocidentalizados da capital chinesa, no no 175 da rua Yongan, encontramos um hotel diferente de todos os outros. Desde 1990, no piso térreo e dentro do edifício do hotel Quianmen Jianguo, representam-se cenas soltas de um género teatral multidisciplinar que terá nascido na China nos finais do séc. XVIII e se designa por Ópera de Pequim. Entre os chineses são três os nomes para uma mesma arte: jingju, jingxi ou pingju, de acordo com o saber de entendidos.

Noite após noite e ano após ano, o Teatro Liyuan composto por actores e músicos maioritariamente agregados à Companhia de Ópera de Pequim, exibe-se perante turistas estrangeiros mas também diante de um sem número de autóctones que acorrem ao hotel-teatro para ver as performances dos mais eximios representantes actuais desta arte cénica bicentenária.

Ao público é dada a opção de se sentar em confortáveis poltronas dispostas como numa plateia, ligeiramente inclinada e muito ampla, ou em redor de mesas e cadeiras inspiradas na decoração Ming, mais próximas estas últimas do palco onde a representação terá lugar. Essa área para refeições à mesa ocupa metade do espaço destinado aos espectadores. Cerca de mil pessoas podem partilhar nesta sala a devoção estética e o prazer da amesentação, independentemente dos lugares que escolhem, pois para aqueles que se encontram sentados em filas umas atrás das outras também existe distribuição de alimentos e bebidas, apenas com um ritual mais moderado.

Para os que decidem aproximar-se mais do palco, e valorizem ao mesmo tempo a atmosfera que se vai criando em torno da refeição, haverá ainda a surpresa de um treinado movimento serpentino de ágeis figurinhas vestidas com discrição e rigor a servir à mesa chá em abundância e outros manjares. Durante toda essa encenação, a coreografia fora de cena acontece, porque esses rapazes e raparigas, com ambas as mãos ocupadas pelo contínuo transporte da baixela, demonstram como aprenderam a escapar, sempre por um triz e só por um bem eficaz, aos efeitos dos aplausos esperados e inesperados de espectadores-clientes que, ao erguerem-se dos seus lugares, empolgados pela expressividade da arte a que assistem, se esquecem de quem silenciosamente os serve. Em qualquer das circunstâncias, em poltronas ou em cadeiras, o menu escolhido requer pagamento em dólares ou yuans, conforme se trate de estrangeiros ou chineses.

Assistir à Ópera de Pequim, complementada por esta modalidade gastronómica, pressupõe que se crie uma disponibilidade interior particular adequada a viver-se o espectáculo como uma festa aberta ao deleite e à sensualidade. Quem sabe se todo este cerimonial combinado entre sala e cena não pretende invocar experiências antigas em espaços próprios das grandes cidades chinesas (Pequim, Xangai e Tianjin), na viragem
Anabela Mendes é professora na Faculdade de Letras da Universidade de Lisbo e investigadora do

Centro de Estudos de Comunicação e Cultura da Universidade Católica Portuguesa. As áreas do saber em que desenvolve a sua actividade são a

Literatura de Expressão Alemã, Cultura Alemã, Estética e Filosofia da Arte, Literatura de Viagens, Ciência e Literatura, Teoria e Estética do Teatro, Sociologia das Artes do Espectáculo. Mantém actividade regular nas áreas da tradução e escrita para teatro, dramaturgia e encenação. 
Entrada do Teatro Liyuan no átrio do hotel Quianmen Jianguo [Arquivo da autora].

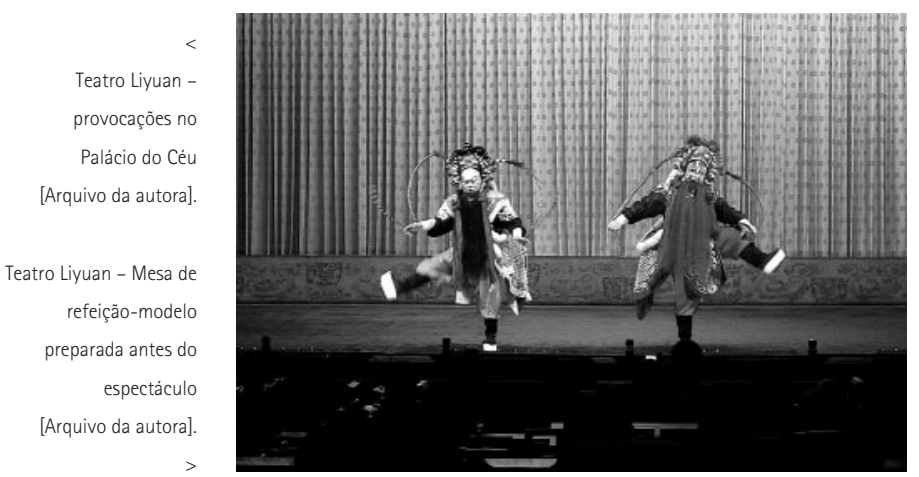

de oitocentos para novecentos? Nessa altura este género de representação tornara-se francamente popular, levando os seus apreciadores a correr muitos dos pequenos teatros e casas de chá em busca dos seus artistas favoritos.

2.

Parece ter sido o desejo de modernizar as estruturas arquitectónicas e técnicas em que a Ópera de Pequim era mostrada - aquele trânsito das caóticas e emaranhadas casas de chá em direcção a salas de teatro construídas e apetrechadas para a apresentação regular destes espectáculos - que não só reinventou o espaço cénico para estas produções, como também trouxe nova vida ao género entre 1895 e 1920. Mas nem a transferência de lugar arquitectónico nem a sua transformação foram então suficientemente pragmáticas para impedir que continuassem a existir, lado a lado, antigos e novos espaços cénicos para a representação da Ópera de Pequim. Esse fenómeno é hoje mais raro, embora não totalmente inviabilizado, sobretudo nas zonas rurais.

0 processo de modernização das condições artísticas e técnicas e a consequente democratização deste género dramático suscitaram ainda uma mais ampla visibilidade e divulgação da Ópera de Pequim nos espaços em que era representada, não sendo de somenos importância para esse movimento reformador que existisse uma maior exigência por parte do público em relação à qualidade artística do trabalho em palco.

0 evidente carácter de sociabilização implementado pela ideia de que "nós somos o lugar onde nos sentamos" (Goldstein 2007: 63) e que referencia este tipo de espectáculo, quer na fase mais antiga da sua história, quer em épocas posteriores e até ao presente, desencadeou também - e sobretudo no período colonial e de convivência alargada entre culturas - a procura de soluções arquitectónicas que dotassem os muitos espaços, onde se representava Ópera de Pequim, de palcos de meia arena
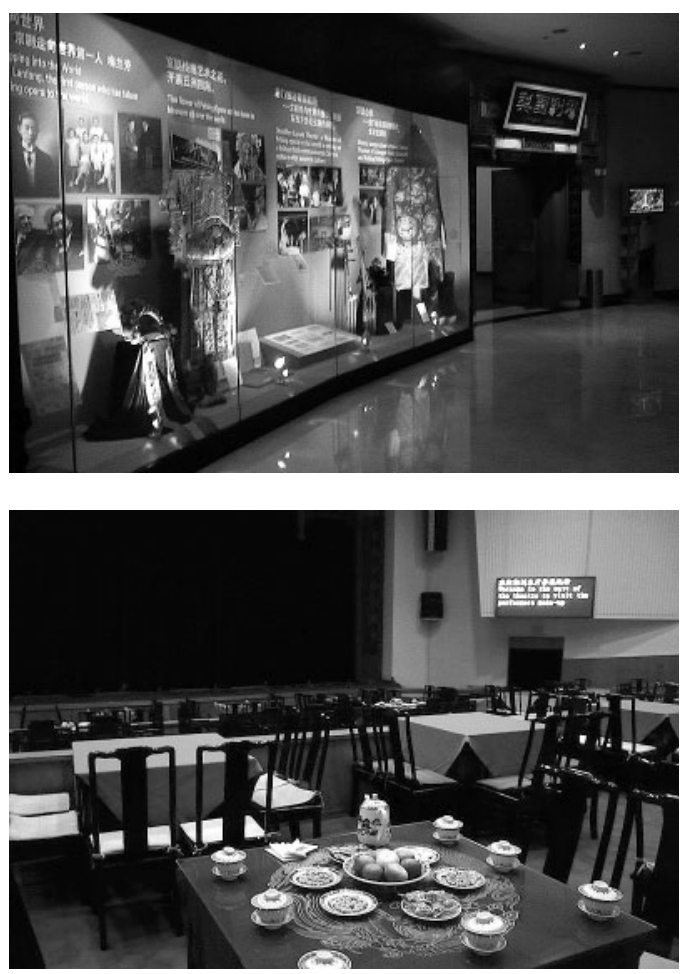

para que a aproximação entre espectadores e cena pudesse ser mais eficaz, tornando-se nesse caso privilegiados não só aqueles que revelavam um poder económico evidente, mas também todos os que se encontravam na esfera de influência política e artística da corte (e posteriormente também no período republicano), através dos quais se tornava mais previsivel o apoio e patrocínio do Imperador a muitas das trupes, cuja qualidade artística fosse manifestamente notável. Este público mais selecto e com gostos estéticos requintados tirava então partido do espaço público dos novos teatros onde assistia à Ópera de Pequim em condições bastante favoráveis.

Tradicionalmente um espectáculo de Ópera de Pequim era visto apenas por homens. A partir dos primeiros anos de novecentos, e reforçando esse espirito de inovação, a assistência alargava-se também a mulheres, estudantes, artistas amadores, activistas, a todo um público que exigia do género um apelativo revigoramento, quer nos temas abordados, quer na potencial modernização dos figurinos, quer também na concepção das partituras musicais que se deveriam adequar ao processo de experimentação em curso.

0 aparecimento em palco de actrizes contratadas para a interpretação de papéis femininos (hoje uma inquestionável realidade) a par de actores com idênticas funções, ou o recurso a novos temas e assuntos com directa eficácia no quotidiano mais próximo do público, que iam sendo introduzidos no repertório clássico, até aí constituído exclusivamente por narrativas épicas e lendárias do espólio nacional, justificam a necessidade de dotar este género artístico de uma constante flexibilidade e experimentalismo. Apesar desta tendência reformadora, observável em diversas frentes, a Ópera de Pequim conserva inalterável até aos nossos dias a mesma matriz com que se iniciou como género. A composição cénica artística constrói-se num articulado entre música, canto, mímica, dança e acrobacia. 


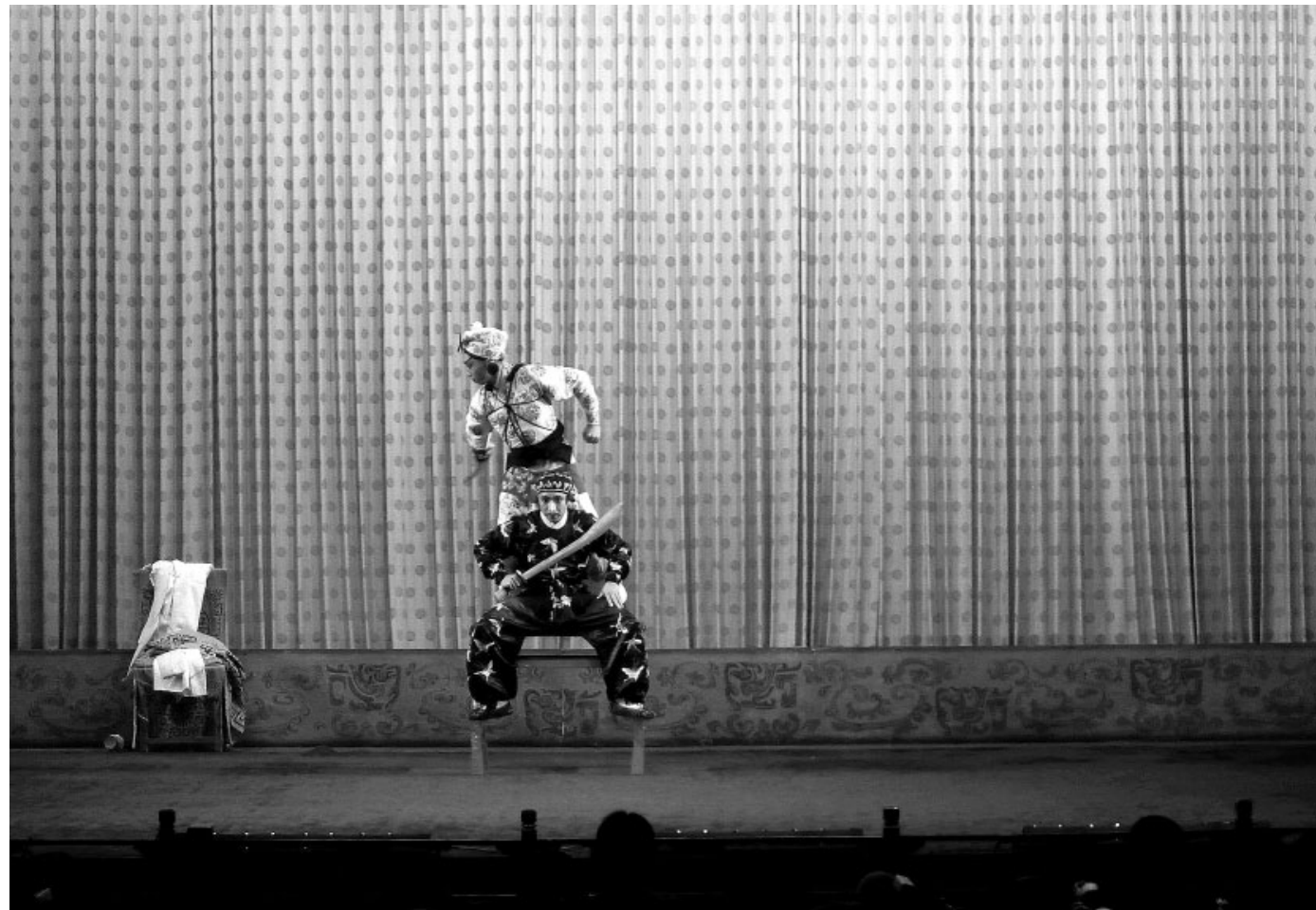

Este renascimento artístico e estrutural segue de perto, em termos históricos, as várias mutações que se operaram na política, na economia e na sociedade chinesas entre 0 fim da dinastia Quing (Xuantong, o último imperador, celebrizado por B. Bertolucci no seu filme homónimo, era um grande apreciador de Ópera de Pequim e seu mecenas) e a conturbada criação da Primeira República, em 1912. Para trás ficavam as duas Guerras do Ópio (1839-42 e 1856-60) e a aberta conflitualidade por interesses económicos entre a Grã-Bretanha e a China. A República Popular e os seus novos valores ideológicos chegariam ao pais do Sol Nascente apenas em 1949, conduzindo este género dramático a um estádio de repentino ostracismo.

Por ser conotada com um passado histórico conservador e inviável no novo contexto político e cultural, a Ópera de Pequim quase é obrigada a abandonar a sua concepção fortemente literária e dramática inspirada numa riquíssima tradição estética de pluralidade artística. 0 apelo para que se posicionasse como um género capaz de revolucionar o sentido da representação numa perspectiva realista e se transformasse numa daquelas janelas abertas preparadas para inspirar no público a vontade de mudança social e política - que esses tempos requeriam - acaba, paradoxalmente, por encontrar resposta na própria natureza e composição dramáticas do género em si.

0 carácter modelável e inventivo que o género cultivara desde sempre, familiarizando gerações com narrativas de fácil identificação e recheadas de simbolismo, arrebatava audiências através de canto, música instrumental, dança acrobática, movimento corporal estilizado como suporte, réplica e fundamento de texto, trajes multicolores e fantasiosos, estaria ou não afinal em contradição com os princípios estéticos e ideológicos dos novos decisores culturais? A resposta ao paradoxo vem então de dentro do próprio género.

A sua natureza intrínseca fornecia à representação aquele carácter que a verdade artística exige de, a partir do próprio estranhamento, criar não a ocultação da realidade mas a sua exposição através do artificio. 0 mundo exterior à representação continuava a ser a fonte inspiradora onde a sede de significado poderia saciar-se. E porque assim era, a Ópera de Pequim como género dramático nacional preservava de forma dialéctica a relação entre sagacidade e simulação, entre engenho, realidade e arte, sem nunca pôr em causa as suas raizes que continuavam a fazer parte de um riquíssimo imaginário colectivo fundado na ancestral tradição literária e artística da China comum também a outros géneros.

Apesar de sujeita a inúmeras vicissitudes, durante as primeiras décadas do período da Revolução Cultural de Mao Tse Tung, a Ópera de Pequim acaba por ser reconhecida na sua essência universal como uma herança genuína da arte dramática chinesa, mantendo-se sob esse desígnio até aos nossos dias.

\section{3.}

Antes que o espectáculo do Teatro Liyuan aconteça, ao cair da noite, já o público circula no feérico foyer do hotel, entrando e saindo das diversas lojas onde o cartão de crédito é a melhor moeda. À venda está tudo o que um ocidental possa apreciar. Não falta à atraente oferta a memória da Ópera de Pequim em livro e em diversas línguas, CDs e DVDs a celebrar o desempenho dos artistas mais recentes, máscaras em papier maché, gesso, madeira, mas não de plástico, todo o tipo de gadgets, roupa inspirada em figurinos trajados por actores e músicos desde tempos antigos.

Já dentro do teatro é possivel assistir-se à fase de caracterização dos actores. Cada um tem um padrão para o rosto. Cada um inscreve na pele uma história estilizada e há muito conhecida. Cada um é artífice em presença de mais um saber que o tempo não apagou. Cada um preparase interiormente para acrescentar a caracterização às artes 

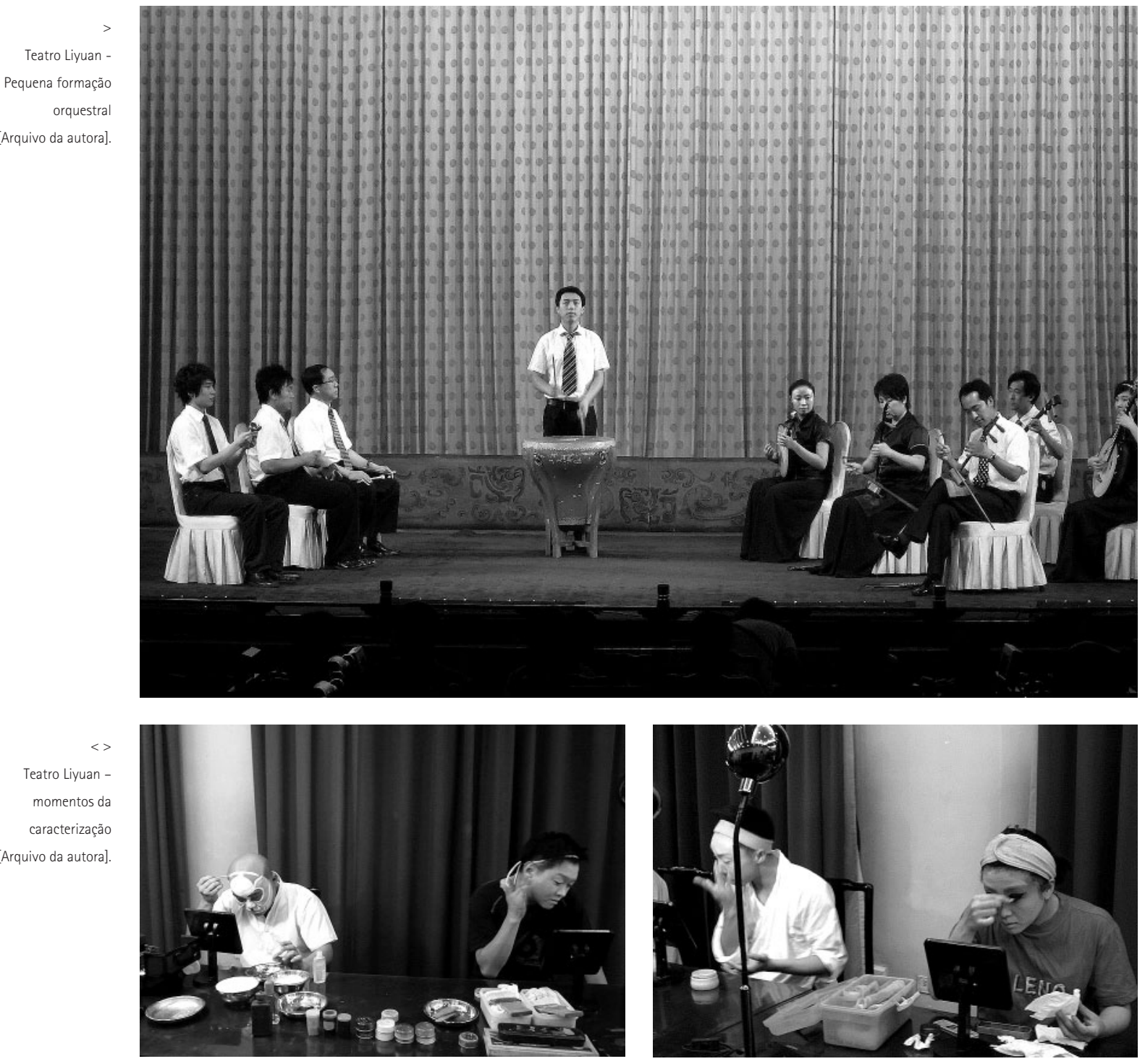

da dança como uma melodia, ao salto, à pirueta, ao vôo livre, ao uso da espada e do sabre, ao canto tímbrico e de amplitude pouco extensa, à representação delineada como partitura, à transformação de um pequeno gesto num grande momento dramático.

$\mathrm{Na}$ exacta precisão de cada momento desta Ópera de Pequim desenvolve-se uma estética de proximidade e distância codificada como sistema epistemológico que distingue claramente entre o princípio da realidade como mimetismo e a construção da representação plasmada num modelo cultural e artístico ancestral. Este modelo, porém, sempre aberto a processos de adaptabilidade e reconversão, de acordo com a evolução da História da China nos últimos dois séculos, parece querer de novo voltar a abraçar mais fortemente as suas reminiscências como procura de identidade.

A estranha beleza do espectáculo do Teatro Liyuan deriva da impossibilidade de nos atermos à ideia de um belo harmonioso desprovido de perturbações. Essa prevalência estética evocada desde sempre no género deixa de fazer sentido para quem não pode acompanhar o que é dito em cena (não há legendas para ninguém), desconhece o porquê da relação sequencial entre os quadros e se senta pela primeira vez diante da Ópera de

Pequim. 0 melhor caminho faz-se então como que pelas margens de um rio, seguindo as suas sinuosidades, respeitando o movimento e a turbulência das correntes, pegando em pequenos seixos, deixando que 0 enfeitiçamento resultante de um entendimento intuitivo daquilo - que em palco se faz - seja capaz de converter em evidência indiscutivel as emoções mais espontâneas provocadas por uma arte vinda do Oriente.

\section{Referência bibliográfica}

GOLDSTEIN, Joshua Goldstein (2007), Drama Kings - Players and Publics in the Re-creation of Peking Opera 1870-1937, Berkeley, Los Angeles / London University of California Press. 